\title{
Studies into severe famine in early life and diabetes in adulthood: the need to control for differences in participant age and location
}

\author{
Chihua $\mathrm{Li}^{1}$ • L. H. Lumey ${ }^{1}$ \\ Received: 18 April 2017 / Accepted: 26 April 2017 /Published online: 10 May 2017 \\ (C) Springer-Verlag Berlin Heidelberg 2017
}

Keywords Chinese famine $\cdot$ Fetal origins $\cdot$ Prenatal exposure long-term effects

To the Editor: In their very interesting study of China's Great Famine of 1959-1962, Wang et al conclude that exposure to famine in the fetal or childhood period may increase diabetes risk in adulthood, and that both the prenatal and postnatal periods may offer critical time windows for the determination of diabetes risk [1]. These conclusions are incomplete and potentially misleading.

Our recent systematic review and meta-analysis of the relationship between prenatal exposure to the Chinese famine and long-term health outcomes shows that uncontrolled age differences between famineexposed individuals and unexposed control individuals in previous studies could explain most of the effects commonly attributed to the famine [2]. This problem cannot be simply fixed by age-adjustment in regression models because there will generally be no overlap in the birth years of those with and without prenatal famine exposure [2]. Therefore, age adjustments will have no impact on risk estimate calculations.

L. H. Lumey

lumey@columbia.edu

1 Department of Epidemiology, Mailman School of Public Health, Columbia University, 722 W 168th Street, 1617A,

New York, NY 10032, USA
In an attempt to avoid the age bias, Wang et al compared the odds of diabetes among study participants born in the same period but in different locations (severely vs moderately affected areas of China). This approach assumes that participants from the areas with varying famine severity are comparable in all respects, except for famine severity. The data presented by Wang et al (Table 4 in their article), however, show a diabetes prevalence of $9.8 \%$ (96/981) among unexposed participants in the severely affected area and only $5.7 \%$ (37/ 651 ) in unexposed participants in the moderately affected area. These numbers only provide weak support for valid comparisons between individuals from severely and moderately affected areas.

Fortunately, the data presented by Wang et al can also be used to directly estimate the relationship between prenatal famine severity and diabetes in adulthood with proper age and area adjustments. To do so, we need to construct an age-balanced control group for those with fetal famine exposure, separately in the areas with moderate and severe famine. Following the age categories presented by Wang et al for unexposed participants (birth years 1963-1997), fetal-stage-exposed participants (birth years 1959-1962), childhood-exposed participants (birth years 1949-1958) and participants exposed in adolescence/young adulthood (birth years 1926-1948), we estimate diabetes prevalence among fetal-stage-exposed participants relative to age-balanced control participants, combining births between 19631997, 1949-1958 and 1926-1948 (Table 1). The mean age for both fetal-exposed participants and age-balanced control individuals in the area of severe famine was 54 years, whilst in the moderate famine area, it was 53 years in the fetal-exposed group and 55 years in the age-balanced control group. As can be seen in 
Table 1 The risk of developing diabetes in later life following exposure to different severities of famine using different control groups

\begin{tabular}{|c|c|c|c|c|c|c|}
\hline \multirow[t]{2}{*}{$\begin{array}{l}\text { Famine } \\
\text { exposure }\end{array}$} & \multicolumn{2}{|c|}{$\begin{array}{l}\text { Fetal-stage-exposed group } \\
\text { (birth year 1959-1962) }\end{array}$} & \multicolumn{3}{|l|}{ Control groups } & \multirow[t]{2}{*}{ OR $(95 \% \mathrm{CI})$} \\
\hline & $\begin{array}{l}\text { No. cases/ } \\
\text { sample } \\
\text { size }\end{array}$ & $\begin{array}{l}\text { Mean age } \\
\text { (years) }\end{array}$ & Control groups by birth year & $\begin{array}{l}\text { No. cases/ } \\
\text { sample } \\
\text { size }\end{array}$ & $\begin{array}{l}\text { Mean age } \\
\text { (years) }\end{array}$ & \\
\hline \multirow[t]{4}{*}{ Severe } & \multirow[t]{4}{*}{$52 / 230$} & \multirow[t]{4}{*}{54} & Unexposed (birth year 1963-1997) & 96/981 & 44 & $2.69(1.85,3.91)$ \\
\hline & & & Childhood (birth year 1949-1958) & $138 / 530$ & 62 & $0.83(0.58,1.20)$ \\
\hline & & & Adolescence/adulthood (birth year 1926-1948) & $90 / 368$ & 71 & $0.90(0.61,1.33)$ \\
\hline & & & $\begin{array}{l}\text { Unexposed, childhood, adolescence/adulthood } \\
\text { combined }\end{array}$ & $324 / 1879$ & 54 & $1.40(1.01,1.95)$ \\
\hline \multirow[t]{4}{*}{ Moderate } & \multirow[t]{4}{*}{$29 / 259$} & \multirow[t]{4}{*}{53} & Unexposed (birth year 1963-1997) & $37 / 651$ & 41 & $2.09(1.26,3.48)$ \\
\hline & & & Childhood (birth year 1949-1958) & $116 / 610$ & 61 & $0.54(0.35,0.83)$ \\
\hline & & & Adolescence/adulthood (birth year 1926-1948) & $63 / 338$ & 72 & $0.55(0.34,0.88)$ \\
\hline & & & $\begin{array}{l}\text { Unexposed, childhood, adolescence/adulthood } \\
\text { combined }\end{array}$ & $216 / 1599$ & 55 & $0.81(0.54,1.22)$ \\
\hline
\end{tabular}

Table 1, the odds for diabetes after fetal exposure relative to age-balanced control participants was elevated (OR 1.40 [95\% CI 1.01, 1.95]) in the severe famine area and not increased (OR 0.81 [95\% CI 0.54, 1.22]) in the moderate famine area $(p=0.04$, Mantel-Haenszel test for homogeneity). These results are free of uncontrolled age effects because of the comparable mean ages of fetal-stage-exposed participants and age-balanced control individuals, and also free of differential area effects because of stratification by study area.

Table 1 further illustrates how sensitive the study results are to the choice of control groups of different ages. The estimated diabetes ORs ranged from 0.54 to 2.69 , with the mean age of control groups ranging from 41 to 72 years across the areas of moderate and severe famine.

We conclude that, based on the data previously presented by Wang et al, the odds for diabetes in adulthood could be increased 1.4-fold after fetal exposure to famine among individuals from the areas affected by severe famine but not moderate famine during China's Great Famine. These estimates are consistent with our findings from the Dutch famine of 1944-1945 [3] and the Ukraine famine of 1959-1962 [4].

These analyses illustrate, again, how important it is to control for age effects and area effects together in analyses carried out to estimate the association between early-life famine exposure and later life health outcomes.
Funding No specific grant from any funding agency in the public, commercial or not-for-profit sectors was received for this letter.

Contribution statement Both authors contributed to the statistical analysis and drafting of the letter, and were responsible for revising the letter critically for important intellectual content, and approved the version to be published.

Duality of interest The authors declare that there is no duality of interest associated with this manuscript.

\section{References}

1. Wang N, Cheng J, Han B et al (2017) Exposure to severe famine in the prenatal or postnatal period and the development of diabetes in adulthood: an observational study. Diabetologia 60:262-269

2. Li C, Lumey LH (2017) Exposure to the Chinese famine of 1959-61 in early life and long-term health conditions: a systematic review and meta-analysis. Int J Epidemiol. doi:10.1093/ije/dyx013

3. Lumey LH, Stein A, Kahn H (2009) Food restriction during gestation and impaired fasting glucose or glucose tolerance and type 2 diabetes mellitus in adulthood: evidence from the Dutch Hunger Winter Families Study. J Dev Orig Health Dis 1(Suppl 1):S164 Abstract

4. Lumey LH, Khalangot MD, Vaiserman AM (2015) Association between type 2 diabetes and prenatal exposure to the Ukraine famine of 1932-33: a retrospective cohort study. Lancet Diabetes Endocrinol 3: 787-794 